round herrings raises interesting problems concerning the origin of tho Dussumieriidae and their relationship to the Clupeidae. The Dussumieriidae can bo split into two sub-families (accepting the round herrings as a whole as a distinet family), the moro primitive Dussumieriinae and the more clupeid-like Spratelloidinae. From the evidence of pelvic scutes, the latter sub-family could now usefully bo divided into two tribes, those with modified and those with unmodified pelvic scutes, for in the latter group, comprising tho southern African forms and $S$. malabaricus, the species all share several further characters distinguishing them from Spratelloides and Jenkinsia (notably tho rathor advanced polvies, the lack of a second supra-maxilla, possession of a toothed premaxilla, and a rather different posteroventral outline to the gill-opening). But except for the first of these differences, the remainder suggest affinities as much with the Dussumieriinae, and ospecially Etrumeus, as with the Clupeidae. It may be that the southern African specios are dorived from forms which lay close to the original separation of tho clupeids and the dussumieriids.

A systematic account of the round herrings is in preparation.

Department of Zoology,

P. J. P. WittTehead

British Museum (Natural History), London, S.W.7.

${ }^{1}$ Chapman, W. M., Proc. Calif. Acad. Sci. (4), 26, 25 (1948).

"Fowler, H. W., Proc. Acad. Nat. Sci. Philad., 87, 361 (1936).

'Sauvage, H.-H., Bull. Soc. Philom, Paris, 7, 156 (1883).

- Bertin, L., Bull. Inst. Oceanogr, Monaco, No. 853, 1 (1943)

'Smith, J. L. B., Ann. Mag. nat. Hist. (12), 2, 97 (1949).

- Barnard, H. K., Ann. S. Afr. Mus., 21, 108 (1925).

\section{Effect of Abrasion on the Cuticular}

\section{Scale Pattern of some Mammalian Fibres}

Tre obsorvation that halo-hairs from lambs 2-4 months old showed a waved, cronate cuticular scale pattern not previously described in sheep, and not shown by halo-hairs taken at birth, suggested that the scale pattern had been drastically changed by weathering. Halo-hairs which had developed tho crenated scale pattern stained much more readily with methylene blue than did those with smooth scale margins, indicating that gross scale damage may bo a factor in the greater affinity for dyes shown by weathered wool.

Fibres from a number of species were treated by rubbing with abrasives (sand paper, jewcllors' rouge) and the following alterations were brought about: halo-hairs taken at birth developed the pattern seen in those taken from oldor lambs; the pattern of the basal region of human hairs (irregular waved mosaic, smooth margins) was converted to a good approximation to the pattern typical of the distal region (wave with ripple to crenate margins); the smooth-margined regular mosaic or diamond petal pattern of the basal part of rat monotrichs and of kolinsky guard hairs was converted to, or towards, a waved, near, crenate pattern. In working on fibres with abrasives it appeared that possibly the lateral edges of the scale wore away first and became invisible, creating a waved pattern, and then the distal margins chipped and wore down, so that the pattern changed towards "near, crenate".

Examination of numerous other fibres and photomicrographs',2 confirmod that in all fibres which showed the waved crenate type of pattern this tends to occur distally, the basal or root end almost invariably showing smooth margins and mosaic or petal pat. terns. Faint traces of the original lateral divisions between scales can often be discorned in the more distal parts. Scale margins of fine wool fibres near the tip in weathered fleeccs have been found to show chipping similar to that which produces cronate patterns on coarser fibres, and the scale pattern of sheep faco hairs is often waved, near, crenate, except close to the root.

Kassenbeck ${ }^{3}$ attributes differences in scale pattern to biomechanical forces within the follicle, and correlates crenate and mosaic scale patterns with ortho- and para-cortex respectively. The facts reported here are not ineompatible with his theory that forces within the folliclo determine such differences as those between mosaic and petal patterns, but is at variance with his explanation of waved crenate pattern types. If the latter are, as now scems probable, due to external friction acting on the fibre above the skin surface it seems unlikely that they can be associated only with orthocortex as Kassenbeck suggests. Hausman ${ }^{4}$ considered that the change in form of the cuticular scalos along the length of mammalian fibres is due to greater external friction towards the tips, but did not suggest that crenations and similar irregularities of the scale margins can be producod by wear.

It is concluded from these obsorvations that probably all mammalian fibros have smooth-margined cuticular scales whon they emerge from the follicle, and very likely that tho patterns are always some form of mosaic or potal; all ripplod and crenate, waved patterns boing derived from the original patterns by wear. The smooth scale margins of wool and adult kemp of sheep are believed to bo due to protection within the fleece. These conclusions aro of significance for fibre identification and also in connexion with dyeing and other commercial processing of mammalian fibros; they give further justification for the customary use of the proximal parts of fibres for electron microscopy and chemical tests, and suggest that comparative work on distal regions and on fibres known to have sufferod abrasion would be valuable.

Wool Biology Unit,

Marca BURns

Department of Textile Industrics, University of Leeds.

${ }^{1}$ Wildman, A. B., The Microscopy of Animal Textile Fibres (Wool Indust. Res. Association, Ieeds, 1954).

${ }^{2}$ Appleyard, H. M., Guide to the Identification of Animal Fibres (Wool Indust. Res. Association, Leeds, 1960).

${ }^{3}$ Kassenbeck, P., Premiere Semaine International de la Textile, Barcelona (1959).

‘ Hausman, L. H., Amer. Nat., 54, 496 (1920).

\section{Stages in the Development of Viviparity in the Amphineura}

The Amphineura are usually consiciered to demonstrate many primitive features among the Mollusca. It is therefore surprising that more attention has not been given to a study of methods of reproduction in the group. Reference to the reproduction of various species is scattered through the literature; but there have been fow attempts since Simroth ${ }^{1}$ to give a general account for the group. The sexes are separate, and it is usually stated that fertilization is external, although one truly viviparous species has been long recognized and is usually quoted. It does not appear to be generally recognized that a complete series can be traced within the group from species in which fertilization is external through those which 